\title{
On the Modeling of Spar-type Floating Offshore Wind Turbines Van-Nguyen Dinh ${ }^{1, a}$ and Biswajit Basu ${ }^{2, b}$ \\ ${ }^{1,2}$ School of Engineering, Trinity College Dublin, Ireland \\ anguyendv@tcd.ie, bbasub@tcd.ie
}

Keywords: Wind energy, floating offshore wind turbine, spar-type, modeling, coupled analysis.

\begin{abstract}
In this paper an overview about floating offshore wind turbines (FOWT) including operating conditions, property and applicability of the barge, tension-leg, and spar floating platforms is described. The spar-floating offshore wind turbines (S-FOWT) have advantages in deepwater and their preliminary design, numerical modeling tools and integrated modeling are reviewed. Important conclusions about the nacelle and blade motions, tower response, effects of wind and wave loads, overall vibration and power production of the S-FOWT are summarized. Computationally-simplified models with acceptable accuracy are necessary for feasibility and preengineering studies of the FOWT. The design needs modeling and analysis of aero-hydro-servo dynamic coupling of the entire FOWT. This paper also familiarizes authors with FOWT and its configurations and modeling approaches.
\end{abstract}

\section{Introduction}

The global warming from the emissions of greenhouse gases is a major concern and the demand in energy is ever increasing. Whereas fossil-based energy is facing resource limit with serious environmental impacts, hydraulic energy is ecology- and disaster-sensitive, and nuclear energy has highly-potential risks with waste disposal difficulty. Energy technology has thus been switched to renewable and clean sources such as sun, wind, biological processes, waves, tides and currents. Solar and wind are the fastest growing renewable energy generation sources [1]. Wind seems to be the most reliable and practical, with its annual increase rate of $25-30 \%[2,3]$. With concentrated effort and technology innovation, wind power could supply up to $12 \%$ of global demand for electricity by 2050 [4]. Wind power contributes greatly to the reduction of greenhouse gases, with $0.5 \mathrm{GtCO}$ reduction (9.2\%) of $\mathrm{CO} 2$ emissions in 2020 and $3.0 \mathrm{GtCO}$ reduction (7.8\%) in 2050 [5].

Onshore wind turbines currently are near their limits and associated with visual constraints and noise impacts that make it increasingly difficult to find appropriate sites for future growth. Offshore wind turbines on the other hand have greatly-reduced visual impacts, less turbulence, and lower noise constraints allowing higher rotor speeds. Although, with current technology the hardware and installation of offshore wind turbines is more expensive and the costs depends largely on water depth and distance from shore. Foundations, installation, and grid connection are significant costs. Nevertheless, offshore wind power plants can produce up to $50 \%$ more electricity than their onshore cousins, due to higher and steadier wind speeds [4]. Offshore wind energy represented $1.8 \%$ of total installed capacity but produced 3.3\% of total wind electricity in 2006 [4]. Moving offshore is said to be driving the wind energy technology development. A worldwide wind atlas based on data from about 8000 locations [6] where wind speeds were calculated at $80 \mathrm{~m}$ illustrates the potential of global offshore wind resources. There is good offshore wind power potential in near-shore deepwater zones in many countries, such as the USA, western coast of South America, Spain, Norway, China, Japan, India and the eastern coast of Australia. Constructions of offshore wind turbine plants is feasible as large offshore turbines can be transported by barges or ships. Land-based wind farm capacity is limited to $50 \mathrm{MW}$ while offshore farms with more than $100 \mathrm{MW}$ capacities are possible [7]. The existing challenges of offshore wind power are the foundations, grids and maintenance.

The cost of fixed mounted offshore wind turbines increases with water depth; their use is consequently not economical in some locations. In deep-water areas, floating wind turbines can be the most cost-effective and reasonable solution [7]. Relevant technology for floating offshore wind 
turbines (FOWT) platforms is available from the offshore oil industry. As a large platform is preferable to minimize the motion responses, and the weight of the wind turbine compared to that of the floating platform is small, it is possible to install larger wind turbines with capacities of 5-10 MW to minimize the power generation cost [8]. The IEA [5] recently reported that offshore wind is one of promising renewable energy technologies while there is the lack of progress, to a lesser extent. This paper therefore aims at reviewing configurations and modeling approaches for FOWTs.

\section{Floating Offshore Wind Turbines}

FOWT systems can be divided into two groups, single turbine system and multi-turbine system [9]. Several initial concepts $[10,11,12,13]$ have considered floaters supporting multiple turbines to reduce floater motion due to smaller thrust height to floater span ratio and to improve economy by employing a single mooring system. However, such systems have to resist high current and wave loads and their turbines suffer wake effects. The floaters supporting a single wind turbine were considered to be more suitable for offshore wind energy $[14,15,16]$. In the single turbine system group, the platform concepts include spar (S), tension-leg platform (TLP) and barge (B) as shown in Fig. 1 [16]. The spar concept uses a long-draft spar moored by catenary or taut lines and achieves stability using ballast to lower the center of mass (CM) below the center of buoyancy $(\mathrm{CB})$. The TLP concept achieves stability through the equilibrium of tensioned taut mooring-lines and the excess buoyancy of the platform. The barge is generally moored by catenary lines and stabilized by its water-plane area. Hybrid models using features of those concepts are also a possibility.
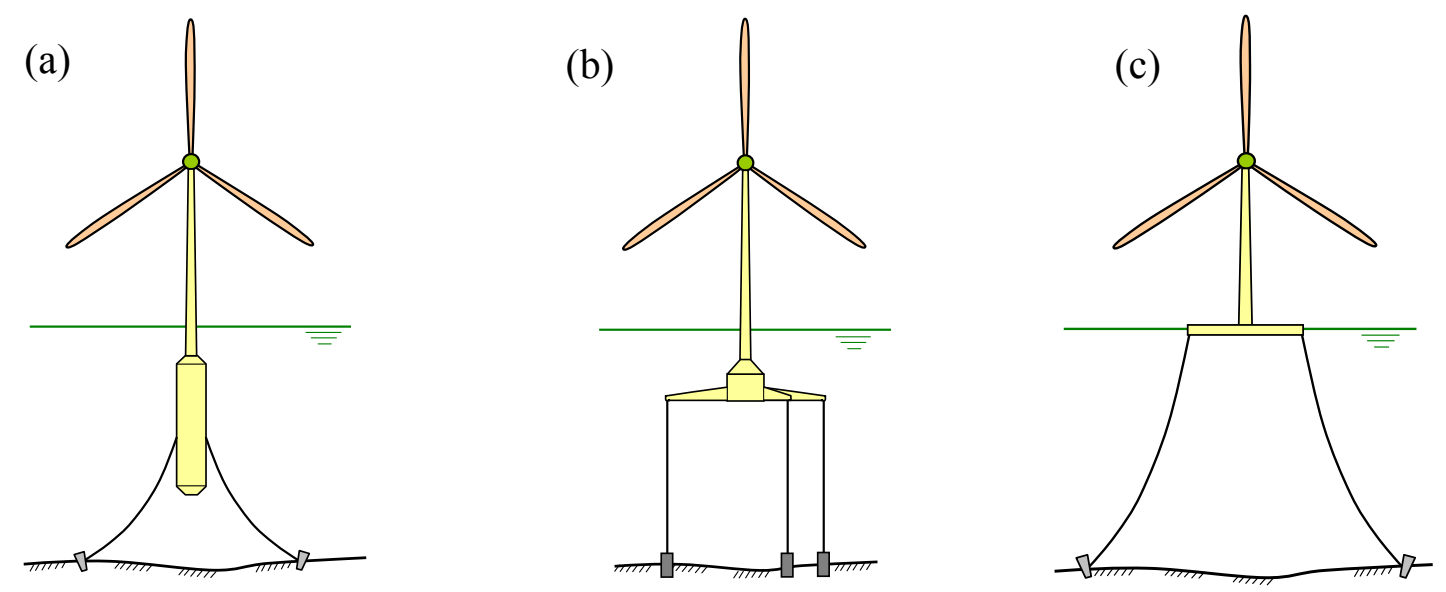

Fig. 1: Single FOWT systems, (a) S-FOWT, (b) TLP-FOWT and (c) B-FOWT.

Choosing a proper single FOWT concept should be based on site and operating conditions such as water depth, environmental conditions, distance to shore, and sea bed properties as depicted in Fig. 2a. A FOWT system consists of mooring system including mooring lines, tendons and clump masses, fairleads and anchors, platform (i.e., spar) and tower, blades, nacelle and hub, gear box, low speed shaft, high speed shaft with its mechanical brake, electrical generator and electronic controller, pitch and yaw mechanisms, and hydraulics system and cooling unit [7]. Each of these single FOWT concepts has its benefits and disadvantages $[7,17,18]$ and are summarized in Table 1 , which shows that the S-FOWT seems to be the most suitable concept for deep-water areas. In addition, the lowered CM is very effective to suppress the pitch and roll motions (Fig. 2b). Ballaststabilization enables cost reduction by using cheap and heavy materials. Besides, the small water plane area and the deep-draft of the spar reduce the heave excitation forces, which, in combination with the mass-dominated behavior of the S-FOWT, provide a very good heave motion performance [7]. The ballast-stabilization and mooring line configuration is suitable for power production purposes from wind turbines. The wind-induced yaw motion can be eliminated by introducing the delta mooring lines with hung clump masses [19] as being used in the HYWDIND concept 
developed by Statoil. Based on the NREL 5-MW wind turbine, the short and long draft S-FOWT models were proposed for medium and deep water, respectively [7].

(a)

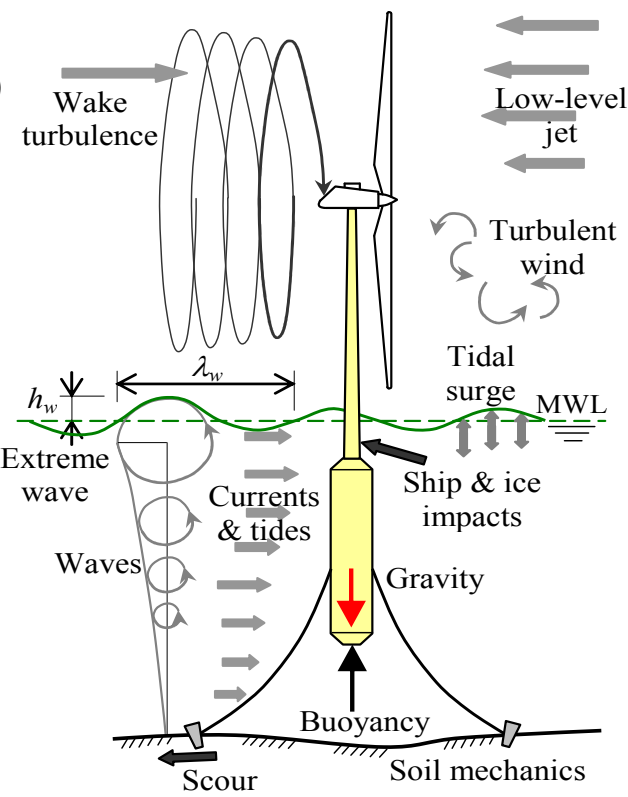

(b)

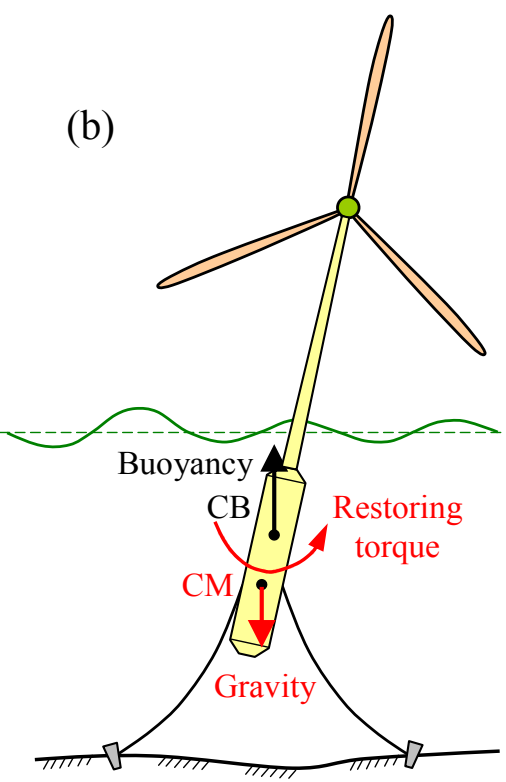

Fig. 2: FOWT system, (a) Operating conditions of a FOWT system and (b) Stability of S-FOWT.

Table 1. Advantages and disadvantages of each single FOWT system concepts.

\begin{tabular}{|c|c|c|}
\hline Spar (S-FOWT) & TLP- FOWT & Barge (B-FOWT) \\
\hline $\begin{array}{l}\text { - Small water line area: Buoyancy } \\
\text { far below free surface, stability } \\
\text { relies on buoyancy/weight } \\
\text { distribution } \\
\text { - Little volume close to free surface } \\
\text {-small wave forces } \\
\text { - Catenary mooring: Low cost and } \\
\text { easy to install. } \\
\text { - Inexpensive platform geometry } \\
\text { - Installation need special } \\
\text { procedures } \\
\text { - Advantageous in natural period, } \\
\text { anchors, operation and } \\
\text { maintenance; challenging in } \\
\text { weight and mooring [17]. } \\
\text { - Not suited for shallow water. }\end{array}$ & $\begin{array}{l}\text { - Small water line area: Buoyancy } \\
\text { far below free surface, stability } \\
\text { relies on positive mooring tension } \\
\text { - Little volume close to free } \\
\text { surface: Small wave forces } \\
\text { - Vertical moorings: Positive } \\
\text { tension needed, expensive } \\
\text { anchors, weight sensitive. } \\
\text { - Complexity of platform depends } \\
\text { upon design, } \\
\text { - Advantageous in natural period, } \\
\text { couple motions, operation and } \\
\text { maintenance; challenging in } \\
\text { anchors and construction [17] } \\
\text { - Not suited for shallow water. }\end{array}$ & $\begin{array}{l}\text { - Large water plane area: } \\
\text { Buoyancy and stability } \\
\text { - Large volume close to free } \\
\text { surface: Large wave forces } \\
\text { - Conventional mooring lines: } \\
\text { Easy to install; large motions } \\
\text { implies large forces. } \\
\text { - Simpler, inexpensive platform } \\
\text { - Deck convenient for operation. } \\
\text { - Advantageous in weight, } \\
\text { anchors; challenging in natural } \\
\text { period, operation and } \\
\text { maintenance [17] } \\
\text { - Easy to install, shallow water } \\
\text { capability, suitable to calm sea } \\
\text { (e.g. the Mediterranean) [7] }\end{array}$ \\
\hline
\end{tabular}

\section{Preliminary Design of Spar-Floating Offshore Wind Tubines}

A conceptual design of a S-FOWT aimed at enabling the economical generation of electricity in offshore locations, typically between 100 and $300 \mathrm{~m}$ water depth is presented [15] where the technical and economic aspect of installing an offshore wind farm based on the concept of S-FOWT and the legal, environmental, fabrication, installation and operation issues are addressed. Simple qualitative analyses of a wind turbine placed on a floating vessel were carried out to address effects of wave-induced vessel motion on the loads experienced by the turbine [2]. The analysis of a FOWT under aero-hydrodynamic loads was described in [20]. Newton-Euler (NE) equations combined with constraint conditions associated with the joints between rigid bodies were employed to analyze a 2-MW downwind S-FOWT in steady wind and no waves and the platform motions 
were found to be meaningfully influenced by gyro moments associated with rotor rotations [21]. Morison's equation was used to compute the wave forces on the S-FOWT in a simulation code [22] where the added mass coefficients are calculated from the linear diffraction theory, the water particle velocities and accelerations are evaluated at the instantaneous positions along the centre axis of spar, and the extrapolated linear wave theory is used for integration of the wave forces along the spar. The mooring lines are represented by linear springs and the S-FOWT is a six degree of freedom (DoF) rigid body and its motion equations are solved in the time domain.

The effect of a stabilizing fin attached at the base of the floating foundation in reducing the pitch motion of a S-FOWT has been investigated [23]. Because of additional hydrodynamic mass of the fin, the rotational motion of the wind turbine about the vertical axis was reduced and the roll, pitch and yaw natural periods were moved away from the wave period range [23]. Different scenarios of progressive drifting of S-FOWTs that are closely spaced in a wind farm to minimize installation costs were investigated where the risk of each scenario, the effect of wind turbine arrangement in a wind farm and the safety factors to be used in the design of moorings were evaluated [24].

\section{Numerical tools for modeling and analysis of FOWT}

Several numerical tools for modeling and analysis of FOWTs have been developed in the literature. The FAST code is a publicly-available aero-elastic simulator for horizontal-axis wind turbines (HAWT) [16,25] and has been extended with additional modules to enable coupled dynamic analysis of FOWTs [16,26]. In FAST, Kane's method combining the advantages of both the Newton-Euler and Euler-Lagrange methods was used. FAST allows for two flapwise and one edgewise bending-mode DOFs per blade and two fore-aft and two side-to-side bending-mode DOFs in the tower. AeroDyn [27] is an aerodynamic subroutine package used together with an aeroelastic code such as FAST to predict the HAWT aerodynamics. AeroDyn contains two models for calculating the effect of wind turbine wakes: the blade element momentum (BEM) and the generalized dynamic-wake theories.

ADAMS ${ }^{\circledR}$ is a commercial and general-purpose code of MSC Software Corporation. It employs multibody-dynamics (MBS) formulations, represents a mechanical system as a series of six-DoF rigid bodies with lumped mass and inertia interconnected by joints, and gives solutions in time domain. Compared to FAST, ADAMS is more complicated but has more features including torsional and extensional DoFs and geometric and material couplings in the blades and tower, blade built-in prebend, and blade-pitch controller actuator dynamics [16]. To model a wind turbine, ADAMS must be connected with a wind turbine aerodynamics code such as AeroDyn where the FAST tools's FAST-to-ADAMS preprocessor can be their interface [28]. USFOS/vpOne code [29] is a hydroelastic code of USFOS Ltd. for dynamic analysis of offshore structures which uses the updated Lagrange formulation and allows geometrical and material nonlinearities and large displacements with moderate strains.

SIMO [30] is a time-domain simulation code for offshore structures with an added external module for rotor aerodynamics to enable modeling of FOWTs [31]. The turbine and support structure are defined by a few rigid bodies and the blade aerodynamics uses BEM with dynamicinflow effects. Individual blade-element forces are then summed and applied in SIMO as a sixcomponent external load on a rotating body. The drag forces on the tower and nacelle are accounted for [26]. HAWC2 [32] is a wind turbine aero-hydro-servo-elastic code of Risø/DTU. It uses combined linear FEM and nonlinear MBS and algebraic constraint equations connecting the bodies.

The commercial software WAMIT ${ }^{\circledR}[33]$ uses a 3-D numerical-panel method in the frequency domain to solve the linearized hydrodynamic radiation and diffraction problems for the interaction of surface waves with offshore platforms of arbitrary geometry. Solution of the radiation problem considers oscillation of the platform in its various modes of motion and yields frequency-dependent hydrodynamic added-mass and damping matrices. The solution of the diffraction problem, which considers the hydrodynamic loads on the platform associated with excitation from incident waves, yields the wave frequency- and direction-dependent hydrodynamic wave-excitation vector. The 
hydrodynamic forces can also be modeled in SIMO code [30] where linear Airy wave theory is assumed and the linear and quadratic potential forces including frequency-dependent excitation, added mass and damping (calculated in WAMIT) and slow drift are accounted for. Viscous drag forces from Morison's equation, mooring-line forces, and body-to-body hydrodynamic coupling force models are considered in SIMO [26]. The hydrodynamic subroutine package HydroDyn [16] includes wave kinematics from the linear Airy wave theory with free-surface corrections; linear hydrostatic restoring, nonlinear viscous drag from incident-wave kinematics, sea currents and platform motion all represented in Morison's equation; the added-mass and damping contributions from linear wave radiation (with free-surface memory effects); and the incident-wave excitation from linear diffraction in regular or irregular seas. The hydrodynamic coefficients in HydroDyn are obtained from the linearized radiation and diffraction problems solved in WAMIT® [33] .

A quasi-static mooring system module was developed by Jonkman [16] for nonlinear mooring line restoring forces of taut or slack catenary mooring lines. It accounts for the apparent weight in fluid, elastic stretching, and seabed friction of each line, but neglects the individual line bending stiffness. As this module can be fully coupled with FAST and ADAMS, it also accounts for the nonlinear geometric restoration of the complete mooring system. RIFLEX [30] is an efficient program system for hydrodynamic and structural analysis of slender marine structures where the environment models include regular and irregular waves and arbitrary current profiles, the load models include external/internal hydrostatic pressures described by the effective tension concept, hydrodynamic loading described by the Morison's equation, and seafloor contacts. The structural models use 3-D FEM and the non-linear material properties include hysteretic material description.

\section{Integrated Modeling and Analysis of Spar-Floating Offshore Wind Turbines}

The entire FOWT composed of rotor, nacelle, tower, platform, mooring system, and wind, wave and hydrodynamic loads should be analyzed using integrated models [19]. SIMO was coupled with RIFLEX to enable a FEM formulation and integrated dynamic analysis of the HYWIND S-FOWT [19] where the numerical results were compared with the model scale test results, the rotor still was modeled as a rigid body but the tower modeled in 12-DOF-beam elements, and various environmental conditions and wind turbine control schemes were considered. In the coupled SIMORIFLEX-HAWC2 programs for simulation of the HYWIND catenary-moored S-FOWTs [34], a very flexible modeling environment where hydrodynamic model is offered by SIMO, the structural modeling is featured by RIFLEX, the rotor and the nacelle were modeled by HAWC2, and the mooring lines and the platform submerged hull were modeled in SIMO-RIFLEX. The HYWIND SFOWT was also analyzed by using the coupled SIMO-RIFLEX-HAWC2 programs for proposing a control algorithm including the tuning method to ensure the desired control frequency which provides stable tower vibration modes [35].

FAST/ADAMS ${ }^{\circledR}$ were coupled with AeroDyn-HydroDyn-WAMIT in a comprehensive integrated modeling of S-FOWTs [16] where the nonlinear restoring mooring loads from the timedomain hydrodynamic loads computation are included in the quasi-static mooring module and are used to obtain the platform motions in each time step. Using the tensions obtained from the quasistaic mooring system and additional loading on the platform from hydrodynamics and loading on the turbine from aerodynamics, FAST or ADAMS then solves the dynamic equations of motion for the accelerations of the rest of the system (platform, tower, nacelle, and blades). Next, FAST or ADAMS integrates in time to obtain new platform and fairlead positions at the next time step [16].

The USFOS/vpOne and HAWC2 codes were compared for a tension-leg S-FOWT using coupled hydroelastic time domain simulations under wave-induced response without wind and aerodynamic effects [36]. The HAWC2 code was used for aerohydro-elastic analysis of a catenary moored SFOWT [37] where a nonlinear FEM model of the mooring system including clump mass and delta lines is modelled in SIMO-RIFLEX for large deflections and applied as nonlinear spring stiffness in HAWC2 through a dynamic link library (DLL) interface, the hydrodynamic loads in HAWC2 code are based on the Morison formula and the instantaneous position of the structure, the Joint North 
Sea Wave Project (JONSWAP) spectrum is used to simulate the irregular long crested waves, and the wave kinematics is obtained from the linear wave theory. In the analysis of coupled wave- and wind-induced motions of a 5-MW S-FOWT in harsh and operational environmental conditions [38], global dynamic responses have been analyzed by aero-hydro-servo-elastic time-domain simulations using the coupled SIMO-RIFLEX and HAWC2 codes [37], the turbulent and constant wind modelling was compared for the motion response, power production and structural responses for several load cases, and the extrapolation methods are applied to estimate the maximum responses.

The feasibility of the catenary moored S-FOWT at a moderate water depth was indicated [39] by analyzing its aero-hydro-servo-elastic responses using the coupled SIMO-RIFLEX-HAWC2 codes [37] where the responses in different environmental conditions are compared. A simplified approach for dynamic response analysis of FOWTs subjected to wave and wind loads was proposed to compute aerodynamic forces with minimized computational time while maintaining acceptable accuracy [40] where a DLL called "TDHMILL" provides the aerodynamic loads as an external input to the SIMO-RIFLEX, the results of the coupled SIMO-RIFLEX-TDHMILL is compared with that of the HAWC2 and very good agreement is obtained. Stochastic dynamic responses and power production of a tension-leg S-FOWT subjected to wind and wave actions were analyzed by using HAWC2 code [41], in which power performance and structural integrity of the system are studied though the negative damping, rotor configuration (upwind/downwind) and tower shadow effects, the operational and survival load cases considering the stochastic wave and wind loading are analyzed to investigate the functionality of that S-FOWT. The modeling aspects of a catenary moored S-FOWT under coupled wave and wind dynamic loads were addressed further [42].

\section{Conclusions Drawn from Modeling and Analysis}

The nacelle and blade motions: The effect of pitch-angle control of blades on the dynamic response of the FOWT for wind speeds above the rated wind speed is important [19]. The standard deviation of the nacelle-surge motion under operational conditions is primarily wind-induced, the statistical characteristics of this motion for constant and turbulent wind are almost the same [38].

Tower responses: The dynamic response mean values are primarily wind-induced and the standard deviations of the responses are primarily wave-induced. The maximum of the responses under operational and survival conditions are wind-induced and wave-induced, respectively. The wind turbulence does not affect the dynamic motion and structural responses significantly. The extreme value of responses can occur under survival conditions [38].

Waves and wind loads: Large turbines experienced slightly greater motion-induced loads than smaller ones but the difference is relatively small. Due to wave-induced motion, the turbine design would not need to be modified significantly from the fixed-base case. However, the tower base loads due to the wave-induced motion are considerable and either a platform with reduced motion or a significantly stronger tower is needed [2]. Hydrodynamic nonlinearities cause excitation of the natural frequencies in the low frequency range more than in the wave frequency range. Nonlinear effects have more influence around the natural frequencies and less at the wave frequency [38].

Overall vibration and frequencies: The three lowest vibration modes of the HYWIND S-FOWT relate basically to rigid body motions and their natural frequencies are much lower than those of the onshore wind turbines. The second lowest (pitching) mode has no damping from the catenary lines and very little damping from the hydrodynamic loads. The tower motion in combination with the aerodynamics and the pitch control will be poor or even negative damped which causes large transient loads [35]. Turbulent wind excites both surge and pitch motions of S-FOWT due to the close frequencies [38]. The nacelle surge motion and the tower-spar interface bending moment and shear force are dominated by rigid body motions rather than elastic deformations [40].

Power production: Turbulence affects power production; for the overrated wind speeds, the mean values and standard deviations of electrical power produced are almost the same for the constant and turbulent wind cases. However, for the below-rated wind speeds, the differences are notable those are attributable to the calm sea state corresponding to low wind speeds. Platform 
motions also influence the power production [38]. The total mass of the S-FOWT at moderate water depth (ShortSpar concept) model is 35\% less than that of the S-FOWT at deep water while the statistical characteristics of the generated power are almost the same for both spars [39]

Final remarks: Simplified models that minimize computational time while maintaining acceptable accuracy are necessary for feasibility and pre-engineering studies of FOWTs. The design should employ modeling and analysis of aero-hydro-servo dynamic coupling of the entire FOWT.

\section{Acknowledgements}

This research is carried out under the EU FP7 funding for the Marie Curie ITN project SYSWIND (Grant No. PITN-GA- 2009-238325). The authors are grateful for the support.

\section{References}

[1] C.M. Wang, T. Utsunomiya, S.C. Wee, Y.S. Choo, Research on floating wind turbines: a literature survey, The IES Journal Part A: Civil \& Struct. Eng., 3(4) (2010) 267-277.

[2] A. R. Henderson, R. Leutz, T. Fujii, Potential for floating offshore wind Energy in Japanese waters. Proceedings of The 12th International Offshore and Polar Eng. Conference, Japan, 2002.

[3] P.D. Sclavounos, S. Lee et al., Floating offshore wind turbines: Tension-leg platform and Taught-leg nuoy concept supporting 3-5 MW wind turbines, EWEC, Poland, 2010.

[4] IEA, Renewable Energy Essentials: Wind, 2008. Available from: www.iea.org

[5] IEA, Energy Technology Perspectives 2012: Pathways to a Clean Energy System, 2012.

[6] C.Z. Archer, M.L. Jacobson, Evaluation of global wind power, J. Geophysic Res. 110 (2005).

[7] M. Karimirad, Stochastic dynamic response analysis of spar-type wind turbines with catenary or taut mooring systems, Ph.D. thesis, Norwegian University of Science and Tech., Norway, 2011.

[8] ISSC (2009) Specialist Committee V.4, Ocean wind and wave energy utilization, 17th International Ship and Offshore Structures Congress, Seoul, Korea.

[9] M.B. Waris, T. Ishihara, Dynamic response analysis of FOWT with different types of heave plates and mooring systems by using a fully nonlinear model, Coupled Sys. Mech., 1(3) (2012).

[10] N. Barltrop, Multiple floating offshore wind farm, Wind Eng., 17(4) (1993) 183-188.

[11] A. Henderson, M. Patel, Rigid-body motion of a floating offshore wind farm, Int. J. Ambient Energy, 19(3) (1998) 167-180.

[12] B.H. Bulder, M.T. van Hees et al., Study to feasibility of and boundary conditions for floating offshore wind turbines, Report 2002-CMC-R43, ECN, MARIN, MSC, TNO, TUD, 2002.

[13] P.V. Phuc, T. Ishihara, A study on the dynamic response of a semi-submersible floating offshore wind turbine system Part 2: Numerical simulation, ICWE12, Australia, 2007.

[14] P. Bertacchi, A. Di Monaco, M. de Gerloni, G. Ferranti, ELOMAR-A moored platform for wind turbines, Wind Eng., 18(4) (1994) 189-198.

[15] K.C. Tong, Technical and economic aspects of a floating offshore wind farm, J. Wind Eng. Industrial Aerodyn., 74-76 (1998) 399-410. DOI:10.1016/S0167-6105(98)00036-1

[16] J.M. Jonkman, Dynamics modeling and loads analysis of an offshore floating wind turbine, Tech. Rep. NREL/TP-500-41958, Nov. 2007, National Renewable Energy Laboratory, Golden, CO.

[17] D. Matha, J.M. Jonkman, A quantitative comparison of the responses of three floating platforms, European Offshore Wind 2009 Conference and Exhibition, Sweden, 2009. 
[18] F.G. Nielsen, Dynamic issues related to floating offshore wind turbines, Presentation, Technical University of Denmark, 2011, Available from: www.comwind.mek.dtu.dk.

[19] F.G. Nielson, T.D. Hanson, B. Skaare, Integrated dynamic analysis of floating offshore wind turbines, OMAE 2006 (ASME), Germany, 2006, DOI: 10.1115/OMAE2006-92291.

[20] A. R. Henderson, M.H. Patel. On the modelling of a floating offshore wind turbine. Wind Energ., 6(2003) 53-86, DOI: 10.1002/we.83

[21] H. Matsukuma, T. Utsunomiya, Motion analysis of a floating offshore wind turbine considering rotor rotation. The IES Journal Part A: Civil and Struct. Eng., 1(4) (2008), 268-279.

[22] T. Utsunomiya, T. Sato, H. Matsukuma, K. Yago, Experimental validation for motion of a spar-type floating offshore wind turbine using 1/22.5 scale model, OMAE 2009 (ASME).

[23] H. Suzuki, A. Sato, Load on turbine blade induced by motion of floating platform and design requirement for the platform, OMAE 2007 (ASME), DOI: 10.1115/OMAE2007-29500.

[24] H. Suzuki, M. Kurimoto, Y. Kitahara, Y. Fukumoto, Progressive drifting of floating wind turbines in a wind farm, OMAE 2009 (ASME), DOI: 10.1115/OMAE2009-79634.

[25] J. M. Jonkman, and M. L. Buhl Jr., FAST User's Guide, Tech. Rep. NREL/EL-500-38230, National Renewable Energy Laboratory, Golden, CO, 2005.

[26] A. Cordle, J.M. Jonkman, State of the art in floating wind turbine design tools, Proceedings of the 21st International Offshore and Polar Engineering Conference, Hawaii, 2011.

[27] D.J. Laino, A.C. Hansen, User's guide to the wind turbine aerody-namics computer software AeroDyn, National Renewable Energy Laboratory, Golden, CO, 2002.

[28] D.J. Laino, A.C. Hansen, User's guide to the computer software routines AeroDyn interface for ADAMS ${ }^{\circledR}$, Prepared for the NREL under Subcontract No. TCX-9-29209-01, 2001.

[29] T. Holmas, USFOS theory manual, version 8-1, Norway, 2004.

[30] MARINTEK, 2008, SIMO/RIFLEX User's Manual, SINTEF, Trondheim, Norway.

[31] Fylling, I., Mo, K., Merz, K, Luxcey, N., 2009. Floating wind turbine - Response analysis with rigid-body model, European Offshore Wind 2009, Stockholm, Sweden.

[32] Larsen, T.J. and A.M. Hansen (2012). How 2 HAWC2, the user's manual, version 4-2, Risø National Laboratory, Denmark. Available from: www.risoe.dtu.dk.

[33] C.H. Lee, J.N. Newman, WAMIT® User Manual, Versions 6.3, WAMIT, Inc., MA, 2006.

[34] B. Skaare, T.D. Hanson, F.G. Nielsen, R. Yttervik, A.M. Hansen, K. Thomsen, T.J. Larsen, Integrated dynamic analysis of floating offshore wind turbines, EWEC, Milan, 2007.

[35] T.J. Larsen, T.D. Hanson. A method to avoid negative damped low frequent tower vibrations for a floating, pitch controlled wind turbine, J. Phys.: Conference Series 75 (2007).

[36] M.Karimirad, Q. Meissonnier, Z. Gao, T. Moan T. Hydroelastic code-to-code comparison for a tension leg spar-type floating wind turbine, Marine Struct., 24(2011)412-35.

[37] M. Karimirad, T. Moan. Extreme dynamic structural response analysis of catenary moored spar wind turbine in harsh environmental conditions, J. Offshore Mech. Arctic Eng. (ASME), 133(2011).

[38] M. Karimirad, T. Moan, Wave- and wind-induced dynamic response of catenary moored spar wind turbine, J. Waterway, Port, Coastal, and Ocean Eng. (ASCE) 138(1)(2012a) 9-20.

[39] M. Karimirad, T. Moan, Feasibility of the application of a spar-type wind turbine at a moderate water depth, Energy Procedia 24 ( 2012c) 340-350. doi: 10.1016/j.egypro.2012.06.117 
Key Engineering Materials 2013, 569-570, pp636 - 643,

URL: www.scientific.net/KEM.569-570.636

[40] M. Karimirad, T. Moan, A simplified method for coupled analysis of floating offshore wind turbines, Marine Struct. 27 (2012b) 45-63, doi:10.1016/j.marstruc.2012.03.003

[41] M. Karimirad, T. Moan, Stochastic dynamic response analysis of a tension leg spar-type offshore wind turbine, Wind Energ. (2012d), doi: 10.1002/we.1537

[42] M. Karimirad, Modeling aspects of a floating wind turbine for coupled wave-wind-induced dynamic analyses, Renewable Energy 53 (2013) 299-305, DOI: 10.1016/j.renene.2012.12.006 